\title{
Gender and Socioeconomic Status in Relation to Weight Perception and Weight Control Behavior in Korean Adults
}

\author{
Hee-Kyung Joha, b Juhwan Oh ${ }^{c}$ Hae-Jeung Lee ${ }^{d, e}$ Ichiro Kawachi ${ }^{f}$ \\ a Department of Medicine, Seoul National University College of Medicine, ${ }^{b}$ Department of

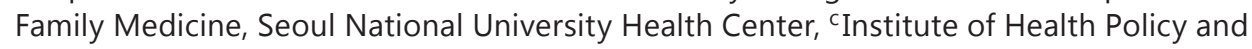 \\ Management, Medical Research Center, Seoul National University, Seoul, South Korea, \\ ${ }^{d}$ Channing Laboratory, Department of Medicine, Harvard Medical School and Brigham and \\ Women's Hospital, Boston, MA, USA, ${ }^{e}$ Center for Nutrition and Policy Promotion, Korea

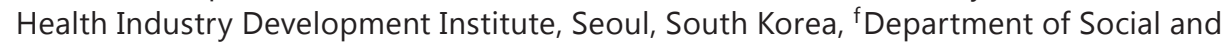 \\ Behavioral Sciences, Harvard School of Public Health, Boston, MA, USA
}

\section{Key Words}

Obesity · Weight perception - Weight control behavior $\cdot$ Gender Socioeconomic status

\begin{abstract}
Aim: In Korea, obesity is more prevalent among men and lower socioeconomic groups. To explain this obesity disparity, we compared weight perception and weight control behavior across gender and socioeconomic status (SES). Methods: We analyzed data from 16,260 participants aged 20 years or older in a nationally representative cross-sectional survey. SES indicators included education and income levels. Weight under-perception was defined when participants considered themselves lighter than their measured BMI status. Either no active or inappropriate weight control (i.e., trying to gain weight in obese individuals) was considered to be unhealthy patterns. Multivariate prevalence ratios were calculated using log-binomial regressions. Results: Men had a higher prevalence of weight under-perception (24.5 vs. $11.9 \%$ ) and unhealthy patterns of weight control behavior (57 vs. $40 \%$ ) than women. Low education level was associated with weight under-perception ( $p_{\text {trend }}=0.022$ in men, $p_{\text {trend }}<$ 0.001 in women). Both education and income levels were significantly associated with patterns of weight control behavior (for education: $p_{\text {trend }}<0.001$ in men and women; for income: $p_{\text {trend }}=$ 0.047 in men, $p_{\text {trend }}<0.001$ in women). Conclusion: Weight perception and weight control behavior significantly varied by gender and SES. Public actions should be directed toward improving perception and behavior of high-risk populations.
\end{abstract}


Joh et al.: Gender and Socioeconomic Status in Relation to Weight Perception and Weight Control Behavior in Korean Adults

\section{Introduction}

Obesity is a major contributor to the global burden of chronic disease and disability [1]. In common with many other countries, Korea experienced a substantial increase in obesity over the last two decades from 13.9\% in 1995 to $31.0 \%$ in 2008 [2, 3]. The trends in Korea exhibit a marked gender differential: while the obesity prevalence in men rose sharply during the past decades, the trend in women has been stable [4]. Obesity is also patterned by socioeconomic status (SES). While lower SES is associated with higher prevalence of obesity in women, the opposite has been observed in men [4-6]. But the most recent data indicate that obesity is shifting toward lower SES even among men [4].

Health inequalities are often a consequence of the unequal distribution of economic, social, and cultural resources. The embodiment of certain aspects of 'cultural capital', such as norms, perceptions, and behaviors, are a key element in transforming social inequality into health inequality [7]. Along these lines, the underlying cause of obesity disparity across social groups can be partly traced to the differing values, weight perception, and weight control behavior across socioeconomic class [8-13]. Accurate weight perception is a first step in preventing obesity, which needs to be followed up with active weight control behavior such as diet and exercise $[8,14]$. Several studies, mostly conducted in Western countries, compared weight perceptions and behaviors across gender and/or SES groups. A tendency for women to over-perceive their weight and for men to under-perceive their weight has been found in postindustrial societies [11, 15-18]. However, these reports have been less consistent in describing the patterning of weight perception or behavior according to SES $[12,13,17,18]$. Several previous studies may have suffered from some biases because they were not based on representative samples $[11,13,15,16]$ and/or used self-reported weight and height $[11$, 15-18]. In addition, evidence on weight perception has been sparse in Eastern settings. Indeed, the evidence reported from predominantly Western countries may not be applicable to the Korean population since individuals' perceptions and behaviors are highly influenced by the social and cultural context [19]. To our knowledge, few nationwide studies in Korea have examined this issue.

Therefore, we evaluated gender and SES differences in weight perception and weight control behavior among Korean adults based on nationally representative data using standardized measurements. We hypothesized that social groups with a higher prevalence of obesity (men and lower SES group) would exhibit a higher tendency toward weight underperception as well as unhealthy patterns of weight control behavior.

\section{Subjects and Methods}

\section{Study Population}

This study was based on data from the Fourth Korea National Health and Nutrition Examination Survey 2007-2009 (KNHANES IV) conducted by the Korea Centers for Disease Control and Prevention. KNHANES is a nationally representative cross-sectional survey using a stratified multistage probability sampling design among non-institutionalized civilians. Additional details about the study are described elsewhere [3].

The KNHANES IV included 24,871 individuals, of which 18,210 respondents were adults aged 20 years or older. We excluded data from the following individuals: those missing data on height, weight, self-perceived weight status, education, or income; pregnant women; or individuals who had any history of cancer within 5 years. After exclusion, the study population consisted of 16,260 adults (6,941 men and 9,319 women).

BMI, Weight Perception, and Weight Control Behavior

Height and weight were measured using standardized equipment and techniques, and BMI was calculated as $\mathrm{kg} / \mathrm{m}^{2}$. Standard BMI cut-points for the Korean population [20] were used to categorize weight status: underweight $\left(<18.5 \mathrm{~kg} / \mathrm{m}^{2}\right)$, normal/overweight $\left(18.5-24.9 \mathrm{~kg} / \mathrm{m}^{2}\right)$, and obese $\left(\geq 25.0 \mathrm{~kg} / \mathrm{m}^{2}\right)$. Self- 
Joh et al.: Gender and Socioeconomic Status in Relation to Weight Perception and Weight Control Behavior in Korean Adults

perceived weight status was obtained by asking participants if they considered themselves to be very light, slightly light, ideal weight, slightly heavy, or very heavy, and then collapsed into light, ideal, and heavy. We compared self-perceived weight status with their measured BMI. Weight 'under-perception' was defined when participants considered themselves lighter than their actual BMI status. Weight 'over-perception' was defined when participants considered themselves heavier than their actual weight status.

Weight control behavior during the past year was assessed by asking participants allowing four possible responses: I tried to i) lose weight; ii) stay the same weight; iii) gain weight; or iv) I did nothing about my weight. Either no active weight control behavior (i.e., doing nothing about weight) or inappropriate weight control (i.e., attempts to gain weight in non-obese individuals, trying to maintain or even gain weight in obese individuals) was considered to be unhealthy patterns $[21,22]$. Participants who responded that they tried to control weight during the past year were questioned about the methods they used (diet, exercise, other methods). In analyses of weight control behavior, underweight individuals $(n=740)$ were excluded.

\section{Indicators of SES and Other Covariates}

Socioeconomic, demographic, and lifestyle factors along with medical history were obtained through direct interviews. We used education and income levels as SES indicators. Education level was classified based on the number of schooling years: elementary or less ( $\leq 6$ years), middle school (7-9 years), high school (10-12 years), or college and above ( $\geq 13$ years). Household-equalized income (total household income / household size ${ }^{0.5}$ ) was categorized into quartiles by gender [23]. Place of residence fell into three categories: metropolitan (Seoul or Pusan), urban (other cities), and rural. Marital status was categorized as unmarried, married living with spouse, and married living without spouse (separated, divorced, or widowed). History of hypertension, diabetes, dyslipidemia, coronary heart disease, and stroke was obtained. Lifestyle factors included alcohol consumption (never or past, moderate, heavy), smoking (never, past, current), and physical activity (sedentary, active). Heavy drinking was defined as consuming $\geq 14$ drinks/ week for men ( $\geq 7$ drinks/week for women) or consuming $\geq 7$ drinks at one time more than once per week for men ( $\geq 5$ drinks for women). Based on the reported overall physical activity, active individuals were defined when they practiced at least moderate activities $\geq 30 \mathrm{~min} /$ day or walking $\geq 1 \mathrm{~h} /$ day on $\geq 5$ days/ week.

\section{Statistical Analyses}

Statistical analyses were performed using SAS version 9.2 (SAS Institute Inc., Cary, NC, USA), and a twotailed $p<0.05$ was considered statistically significant. To make the results representative of the entire Korean population, we took into account the KNHANES complex sampling design and applied survey weights for the estimates of means, prevalence, and standard errors. Age-adjusted prevalence was derived by direct standardization to the year 2005 Korean census population.

Prevalence ratios (PRs) and 95\% confidence intervals (CIs) were estimated by log-binomial regression using SAS PROC GENMOD's [24]. Estimating prevalence ratios is usually preferable to odds ratios when outcomes are not rare in cross-sectional studies [24]. To estimate the associations with education and income independent of confounding factors, PRs were adjusted for age, BMI, marital status, place of residence, history of chronic disease, and lifestyle factors. Education and income were mutually adjusted for each other. In the models for weight control behavior, physical activity was not adjusted because leisure time activity may be a part of the outcome variable itself. Tests for trend were conducted by treating education and income levels as continuous terms. Unless otherwise noted, PRs from multivariate models are presented in the results.

\section{Results}

Table 1 presents the characteristics of the study population. The prevalence of obesity was higher in men (36.8 vs. $27.4 \%$ ), but more women considered themselves heavy and reported active attempts to control weight. Men showed a high prevalence of obesity across the age groups of 20-69 years, whereas prevalence in women rose with increasing age (fig. 1A). Although SES disparities in obesity prevalence were not obvious in men, low SES was associated with a higher prevalence in women (fig. 1B). For weight control methods, men 
Joh et al.: Gender and Socioeconomic Status in Relation to Weight Perception and Weight Control Behavior in Korean Adults

Table 1. Characteristics of the Korean adults aged 20 years or over in the Korean National Health and Nutrition Examination Survey (KNHANES) 2007-2009

\begin{tabular}{|c|c|c|c|c|}
\hline & \multicolumn{2}{|l|}{ Men } & \multicolumn{2}{|c|}{ Women } \\
\hline & $\%$ & $95 \% \mathrm{CI}$ & $\%$ & $95 \% \mathrm{CI}$ \\
\hline \multicolumn{5}{|l|}{ Age } \\
\hline $20-39$ years & 44.2 & $42.2-46.1$ & 40.0 & $38.3-41.7$ \\
\hline $40-59$ years & 39.9 & $38.2-41.7$ & 39.2 & $37.6-40.7$ \\
\hline$\geq 60$ years & 15.9 & $14.9-16.9$ & 20.8 & $19.6-22.1$ \\
\hline \multicolumn{5}{|l|}{ Education } \\
\hline Elementary or less $\leq 6$ years & 13.4 & $12.3-14.6$ & 27.0 & $25.4-28.5$ \\
\hline Middle school 7-9 years & 10.4 & $9.4-11.4$ & 10.3 & $9.5-11.1$ \\
\hline High school $10-12$ years & 28.8 & $27.2-30.4$ & 31.4 & $30.0-32.8$ \\
\hline College and above $\geq 13$ years & 47.4 & $45.3-49.4$ & 31.3 & $29.7-33.0$ \\
\hline \multicolumn{5}{|l|}{ Income 10,000 Korea Won, mean } \\
\hline 1st quartile lowest & 54 & $53-56$ & 51 & $50-53$ \\
\hline 2nd quartile & 105 & $104-107$ & 97 & $95-99$ \\
\hline 3rd quartile & 159 & $156-161$ & 149 & $146-151$ \\
\hline 4th quartile highest & 339 & $312-367$ & 316 & $294-339$ \\
\hline \multicolumn{5}{|l|}{ Marital status } \\
\hline Unmarried & 23.0 & $21.3-24.7$ & 14.5 & $13.3-15.8$ \\
\hline Married living with spouse & 71.5 & $69.7-73.3$ & 67.6 & $66.0-69.1$ \\
\hline Married living without spouse & 4.8 & $4.1-5.4$ & 17.4 & $16.4-18.5$ \\
\hline \multicolumn{5}{|l|}{ Residence } \\
\hline Rural & 18.1 & $14.7-21.5$ & 17.8 & $14.6-21.0$ \\
\hline Urban & 54.4 & $50.7-58.1$ & 53.5 & $49.9-57.0$ \\
\hline Metropolitan & 27.5 & $25.4-29.6$ & 28.7 & $26.7-30.7$ \\
\hline History of chronic diseas ${ }^{\mathrm{e}} \mathrm{a}$ & 22.5 & $21.2-23.7$ & 22.2 & $21.0-23.4$ \\
\hline \multicolumn{5}{|l|}{ Alcohol consumption } \\
\hline Never/past & 13.6 & $12.5-14.7$ & 34.8 & $33.4-36.2$ \\
\hline Moderate & 46.6 & $45.0-48.1$ & 53.5 & $52.2-54.8$ \\
\hline Heavy & 39.8 & $38.3-41.3$ & 11.7 & $10.8-12.5$ \\
\hline \multicolumn{5}{|l|}{ Smoking } \\
\hline Never & 19.1 & $17.8-20.3$ & 86.4 & $85.4-87.5$ \\
\hline Past & 33.6 & $32.2-34.9$ & 6.6 & $5.9-7.3$ \\
\hline Current & 47.4 & $45.8-48.9$ & 6.9 & $6.2-7.7$ \\
\hline \multicolumn{5}{|l|}{ Physical activity } \\
\hline Sedentary & 52.4 & $50.7-54.1$ & 58.9 & $57.3-60.5$ \\
\hline Active & 47.6 & $45.9-49.3$ & 41.1 & $39.5-42.7$ \\
\hline \multicolumn{5}{|l|}{ BMI } \\
\hline Underweight $<18.5 \mathrm{~kg} / \mathrm{m}^{2}$ & 3.2 & $2.7-3.8$ & 6.2 & $5.4-6.9$ \\
\hline Normal/overweight $18.5-24.9 \mathrm{~kg} / \mathrm{m}^{2}$ & 60.0 & $58.6-61.4$ & 66.5 & $65.3-67.7$ \\
\hline Obesity $\geq 25 \mathrm{~kg} / \mathrm{m}^{2}$ & 36.8 & $35.4-38.2$ & 27.4 & $26.2-28.5$ \\
\hline \multicolumn{5}{|l|}{ Self-perceived weight status } \\
\hline Light & 20.3 & $19.0-21.7$ & 13.6 & $12.7-14.5$ \\
\hline Ideal & 40.9 & $39.4-42.4$ & 40.1 & $38.9-41.4$ \\
\hline Heavy & 38.7 & $37.2-40.3$ & 46.3 & $45.0-47.5$ \\
\hline \multicolumn{5}{|l|}{ Weight control attempt } \\
\hline Tried to lose weight & 33.0 & $31.4-34.5$ & 45.9 & $44.6-47.2$ \\
\hline Tried to maintain weight & 12.3 & $11.3-13.3$ & 12.0 & $11.1-12.8$ \\
\hline Tried to gain weight & 9.0 & $8.0-10.0$ & 2.9 & $2.4-3.3$ \\
\hline Did nothing about weight & 45.7 & $44.1-47.3$ & 39.3 & $37.9-40.6$ \\
\hline
\end{tabular}

${ }^{a}$ Any history of hypertension, diabetes, dyslipidemia, coronary heart disease, and stroke. 

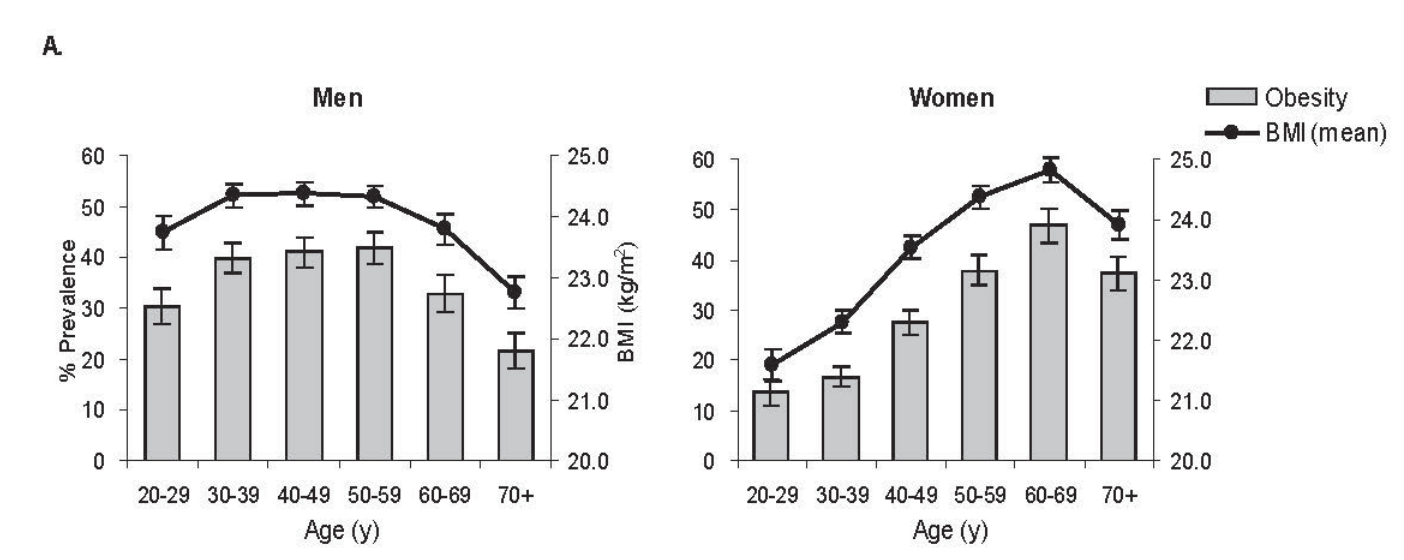

B.
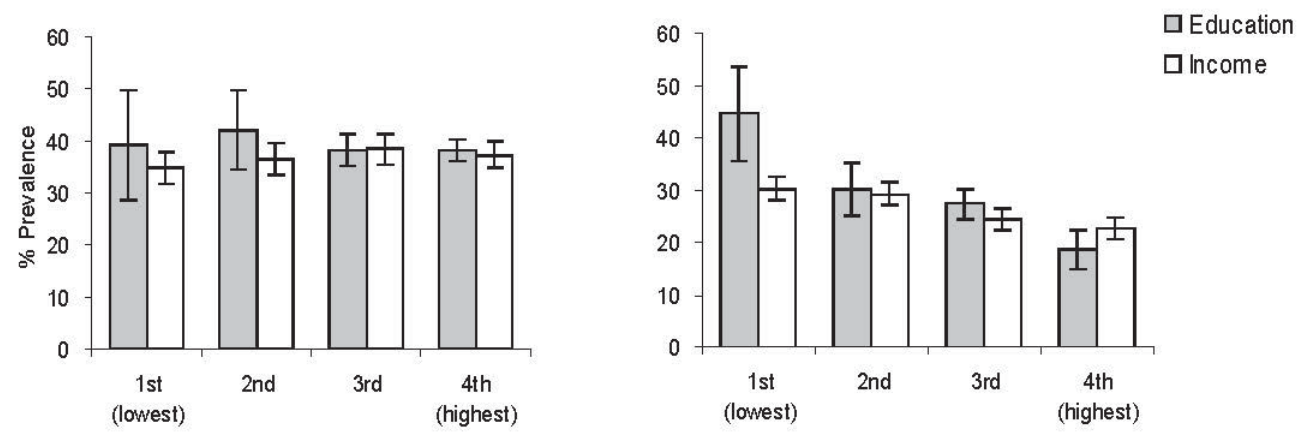

Fig. 1. Age-specific or age-adjusted prevalence of obesity (BMI $\geq 25 \mathrm{~kg} / \mathrm{m}^{2}$ ) by A gender and B socioeconomic status (age-adjusted prevalence of obesity by education and income; age was adjusted by direct standardization to the year 2005 Korean census population; education level: 1 st = elementary or less, $2 \mathrm{nd}=$ middle school, 3rd = high school, 4th = college and above; income level: represents quintiles in each gender) in the Korean National Health and Nutrition Examination Survey (KNHANES) 2007-2009.

preferred exercise $(39.1 \%)$ to dietary restriction $(21.9 \%)$, but women used either exercise $(43.6 \%)$ or dietary restriction $(38.3 \%)$.

\section{Weight Perception and Weight Control Behavior by Gender}

The levels of weight perception and weight control behavior appreciably differed between genders (table 2). Men had a twofold higher prevalence of weight under-perception than women (24.5 vs. $11.9 \%$ ); more than half the men reported no active or inappropriate weight control behavior. Moreover, men and women showed different patterns of weight perception and behavior across age groups (fig. 2). For men under 60 years, perception and behavior were not markedly different across the four age groups. By contrast, women's weight underperception and no active or inappropriate behavior were positively associated with age.

Inappropriate weight control behavior was most prevalent among the younger men.

\section{Weight Perception and Weight Control Behavior by SES}

Weight perception and control behavior were patterned by SES in both genders (table 3). Low education level was associated with weight under-perception with significant linear trends ( $\mathrm{p}_{\text {trend }}=0.022 \mathrm{in}$ men, $\mathrm{p}_{\text {trend }}<0.001$ in women), and women showed a steeper gradient 
Joh et al.: Gender and Socioeconomic Status in Relation to Weight Perception and Weight Control Behavior in Korean Adults

Table 2. Age-adjusted prevalence ${ }^{\mathrm{a}}(95 \% \mathrm{CI})$ of weight perception and weight control behavior by gender in the KNHANES $2007-$ 2009

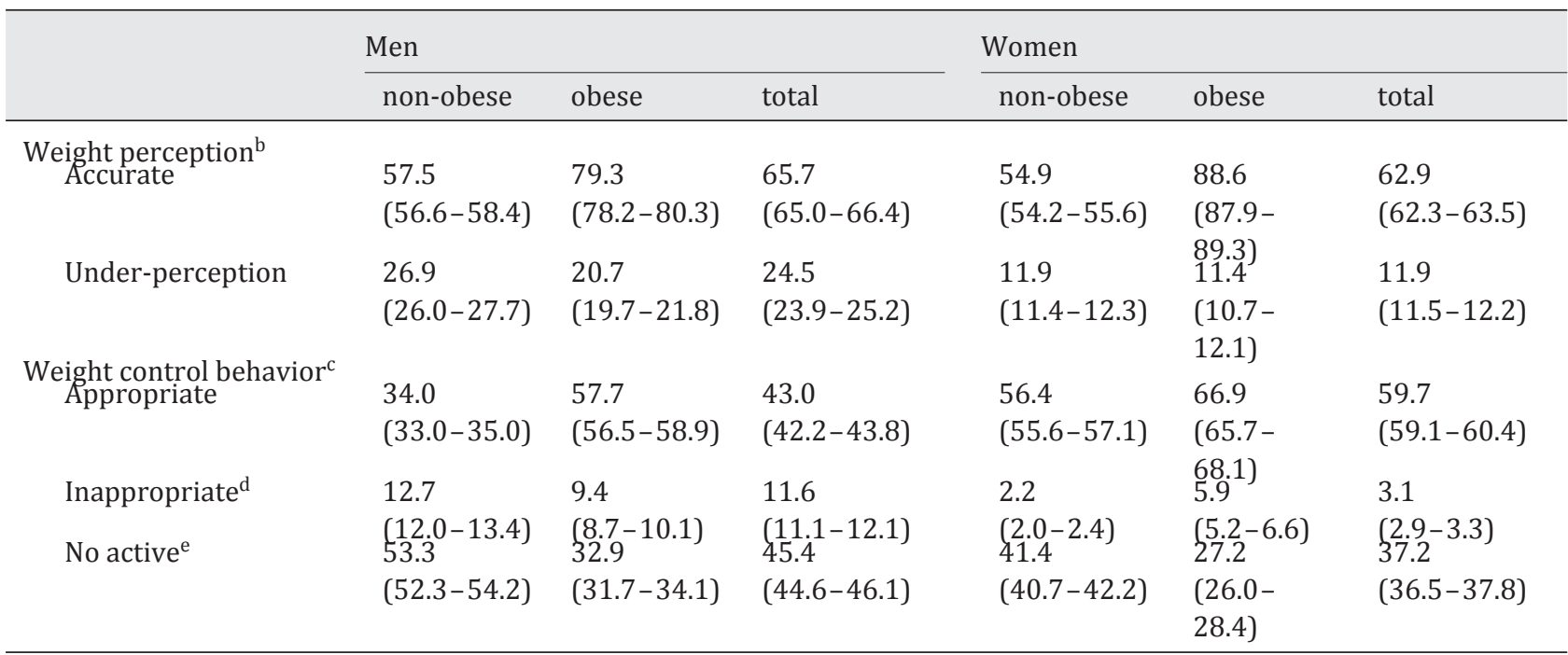

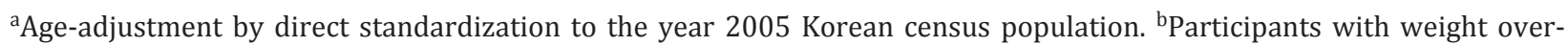
perception were omitted. 'Underweight participants (BMI $<18.5 \mathrm{~kg} / \mathrm{m}^{2}$ ) were excluded from analyses. ${ }^{\mathrm{d}}$ For obese participants $\left(\mathrm{BMI} \geq 25 \mathrm{~kg} / \mathrm{m}^{2}\right)$ : 'tried to gain weight' or 'tried to maintain weight'; for non-obese: 'tried to gain weight'. 'For obese and nonobese participants: 'did nothing about weight'.
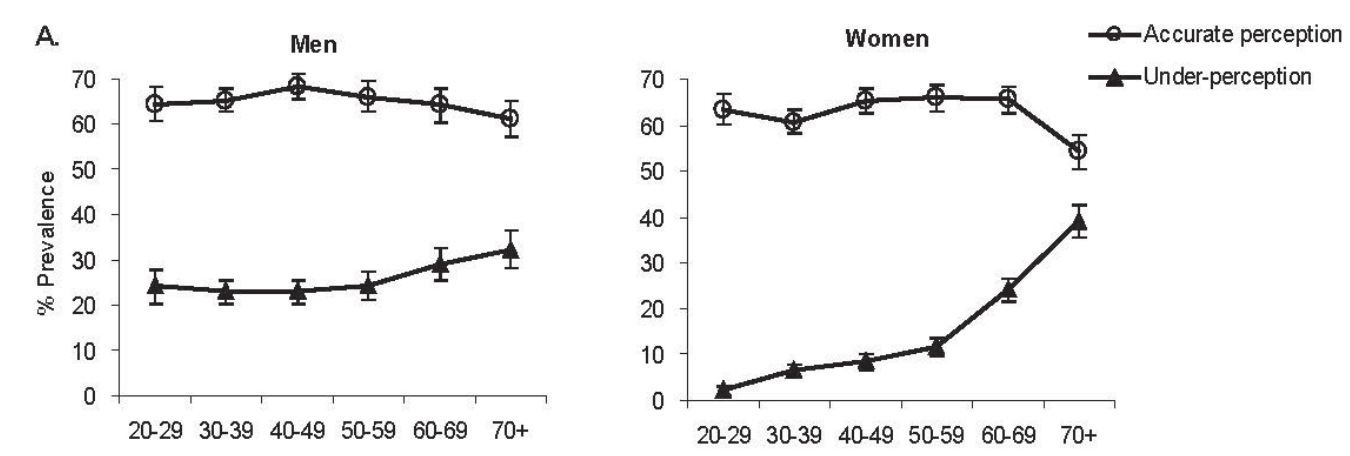

B.
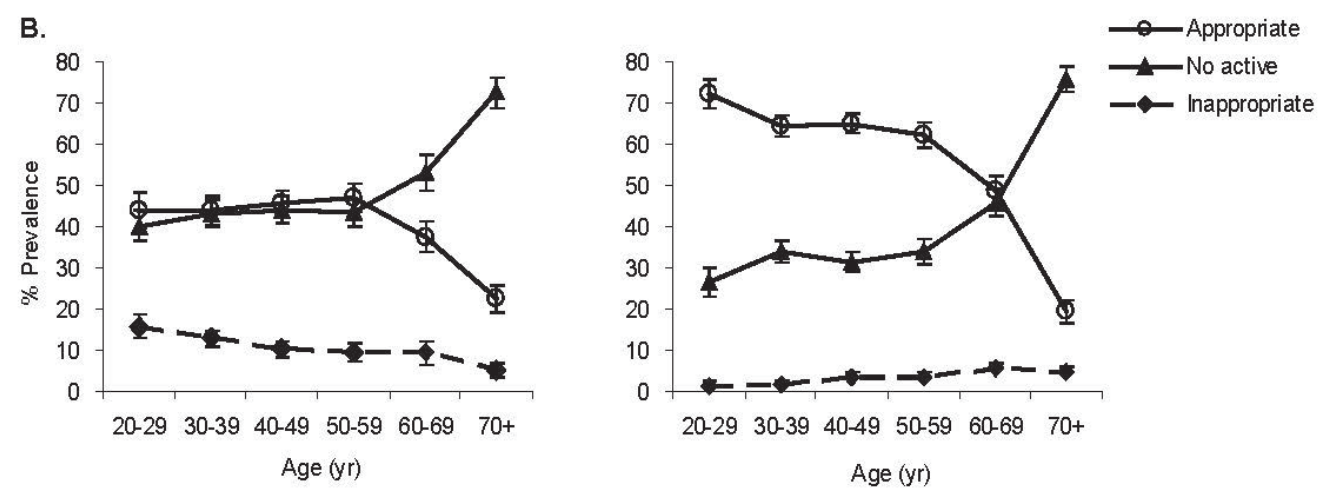

Fig. 2. Age-specific A weight perception (participants with weight over-perception were omitted) and B weight control behavior (underweight participants with $\mathrm{BMI}<18.5 \mathrm{~kg} / \mathrm{m}^{2}$ were excluded from analyses) by gender 
Joh et al.: Gender and Socioeconomic Status in Relation to Weight Perception and Weight Control Behavior in Korean Adults

Table 3. Multivariate prevalence ratios (95\% CI) of weight under-perception and unhealthy weight control behavior by socioeconomic status and other covariates

Weight under-perception ${ }^{\mathrm{a}}$

\begin{tabular}{ll}
\hline men & women \\
$(n=6,941)$ & $(n=9,319)$
\end{tabular}

No active or inappropriate weight control behavior $\mathrm{b}$

\begin{tabular}{ll}
\hline men & women \\
$(n=6,695)$ & $(n=8,825)$
\end{tabular}

Weight perception

Accurate

Under-perception

(among non-obese)

Under-perception (among obese)

Age (10 years)

BMI $\left(\mathrm{kg} / \mathrm{m}^{2}\right)$

Education

Elementary or less ( $\leq 6$ years)

Middle school (7-9 years)

High school (10-12 years)

College and above ( $\geq 13$ years)

$\mathrm{p}_{\text {trend }}$

Income

1st quartile (lowest)

2nd quartile

3rd quartile

4th quartile (highest)

$\mathrm{p}_{\text {trend }}$

Marital status

Unmarried

Married living with spouse

Married living without spouse

Residence

Rural

Urban

Metropolitan

History of chronic disease

No

Yes

Alcohol consumption

Never/past

Moderate

Heavy

Smoking

Never

Past

Current

Physical activity

Sedentary

Active $\begin{array}{ll}1.00(0.96-1.04) & 1.41(1.33-1.49) \\ 0.87(0.86-0.88) & 0.94(0.92-0.95) \\ & \\ 1.20(1.04-1.38) & 2.34(1.86-2.95) \\ 1.13(0.98-1.31) & 1.40(1.08-1.83) \\ 1.18(1.06-1.32) & 1.25(0.99-1.56) \\ 1 \text { (ref) } & 1 \text { (ref) } \\ 0.022 & <0.001\end{array}$

$1.08(0.96-1.22) \quad 1.19(1.06-1.34)$

$1.08(0.96-1.21) \quad 1.08(0.96-1.22)$

1 (ref)

0.190

1 (ref)

$1.02(0.89-1.17)$

$0.97(0.79-1.19)$

1 (ref)

$1.01(0.92-1.11)$

$1.04(0.93-1.16)$

1 (ref)

0.99 (0.90-1.09)

1 (ref)

$0.98(0.88-1.08)$

$1.04(0.93-1.16)$

1 (ref)

$0.88(0.79-0.99)$

0.94 (0.85-1.05)

1 (ref)

1.02 (0.94-1.10)
1 (ref)

0.011

1 (ref)

$1.74(1.17-2.60)$

$1.62(1.07-2.45)$

1 (ref)

$0.87(0.79-0.96)$

$0.74(0.65-0.85)$

1 (ref)

1.04 (0.95-1.13)

1 (ref)

$0.98(0.89-1.08)$

0.87 (0.69-1.09)

1 (ref)

$0.96(0.79-1.15)$

$1.06(0.92-1.21)$

1 (ref)

1.04 (0.96-1.14)
$1.05(0.94-1.18) \quad 1.12(0.99-1.26)$

1 (ref) 1 (ref)

$1.09(1.03-1.15) \quad 1.11(1.04-1.18)$

$1.28(1.19-1.38) \quad 1.30(1.21-1.39)$

$1.01(1.00-1.03) \quad 1.06(1.03-1.08)$

$0.93(0.92-0.93) \quad 0.95(0.94-0.95)$

$1.15(1.08-1.22) \quad 1.82(1.67-1.99)$

$1.11(1.04-1.18) \quad 1.26(1.13-1.40)$

$1.13(1.08-1.19) \quad 1.00(0.92-1.09)$

1 (ref) 1 (ref)

$<0.001<0.001$

$1.09(1.03-1.15) \quad 1.07(1.04-1.11)$

$1.09(1.03-1.15) \quad 1.01(0.98-1.05)$

1 (ref)

0.047

1 (ref)

$<0.001$

1 (ref) 1 (ref)

$0.94(0.89-0.98) \quad 1.36(1.19-1.55)$

$0.96(0.90-1.01) \quad 1.35(1.18-1.55)$

1 (ref) 1 (ref)

$0.99(0.96-1.03) \quad 0.96(0.91-1.00)$

$0.97(0.93-1.01) \quad 0.93(0.88-0.98)$

1 (ref) 1 (ref)

$0.97(0.93-1.01) \quad 0.96(0.95-0.98)$

1 (ref)

$1.02(0.98-1.07)$

1 (ref)

$0.90(0.86-0.95)$

$1.04(1.01-1.08) \quad 0.88(0.80-0.96)$

1 (ref) 1 (ref)

$0.98(0.93-1.04) \quad 1.02(0.97-1.07)$

$1.03(0.98-1.09) \quad 1.00(0.99-1.01)$

1

aSimultaneously adjusted for all variables in the model. ${ }^{b}$ Adjusted for the variables in footnote "a" except for physical activity; underweight participants $\left(\mathrm{BMI}<18.5 \mathrm{~kg} / \mathrm{m}^{2}\right)$ were excluded. 
Joh et al.: Gender and Socioeconomic Status in Relation to Weight Perception and Weight Control Behavior in Korean Adults

across education levels than men. Likewise, a low income level was associated with weight under-perception before controlling for education level (for the bottom quartiles: multivariate $\mathrm{PR}=1.13$ (95\% CI 1.01-1.27) in men; PR = 1.17 (95\% CI 1.05-1.29) in women). But further adjustment for education level attenuated most of the income relationships, although women in the lowest income quartile had a significantly higher PR of 1.19 (95\% CI 1.06-1.34). Weight under-perception in turn was associated with no active or inappropriate weight control behavior, especially among obese participants.

Both education and income levels were significantly associated with weight control behavior (for education: $p_{\text {trend }}<0.001$ in both men and women; for income: $p_{\text {trend }}=0.047$ in men, $\mathrm{p}_{\text {trend }}<0.001$ in women). These associations were persistent even after controlling for the effects of weight under-perception (for education: $\mathrm{p}_{\text {trend }}<0.001$ in both men and women; for income: $\mathrm{p}_{\text {trend }}=0.07$ in men, $\mathrm{p}_{\text {trend }}<0.001$ in women). These relationships were similarly observed in either no active or inappropriate weight control (data not shown).

\section{Association with Other Covariates}

Marital status and place of residence were associated with weight perception and behavior, especially in women. Married women tended to under-perceive their weight and be less active in weight control than unmarried women; women living in urban areas showed a lower likelihood of weight under-perception and were more active in weight control than those in rural areas. Alcohol consumption was linked to weight control behavior, but in different ways by gender. Heavy drinkers among men tended to have unhealthier patterns of weight control behavior than non-drinkers, while the opposite was found among women.

\section{Discussion}

Weight perception and weight control behavior significantly varied by gender and SES in Korean adults. Low SES groups had a higher prevalence of weight under-perception and unhealthy patterns of weight control behavior, and the overall prevalence was higher in men than in women. These broad patterns are consistent with the increasing trends in obesity among men and low SES groups in Korea, suggesting that disparities in perception and behavior across social groups might be one of the underlying mechanisms of the obesity epidemic.

The gender difference found in this study may stem from the sociocultural milieu in Korea. One explanation is that norms about ideal body weight may be different between genders. Weight perception is closely linked to sociocultural norms about ideal body weight, which are susceptible to change as societal attitudes toward obesity change [18]. In the traditional Korean culture, a plump body shape used to be desired as a symbol of health, wealth, and social stature, a common preference in developing countries with food scarcity [8, 25, 26]. This traditional ideal was dominant until quite recently in Korea, but rapid economic development and westernization since the 1970s led to a preference shift toward smaller body size, especially in women. In contemporary Korean society, women's thinness is equated with physical attractiveness and held up as an ideal of feminine beauty [27, 28]. In our results, younger women had a significantly lower prevalence of weight under-perception than older women, which suggests a generational shift in body weight norms. By contrast, age was not associated with weight perception in men. Moreover, a considerable proportion of normal or overweight young men perceived themselves to be underweight and reported attempting to gain weight. This suggests that many men, even from younger generations, continue to adhere to the traditional ideal of body shape - i.e., larger body sizes are viewed as symbols of masculinity and power. Second, the extent of obesity stigmatization and societal pressures for 
Joh et al:: Gender and Socioeconomic Status in Relation to Weight Perception and Weight Control Behavior in Korean Adults

thinness is disproportionately focused on women in Korea [29] as in other developed societies $[8,18]$. Obese women are stigmatized as lacking in self-control, whereas social attitudes are more lenient and relatively neutral for obese men [14]. Lastly, regional culture may also moderate women's attitudes toward weight. According to a recent international survey, young Korean and Japanese women currently express the highest levels of weight concern and weight control attempts, while men have fairly similar levels across regions [15].

In this study, weight perception was more closely linked to education level, whereas weight control behavior was associated with both education and income levels, even after controlling for the effects of weight perception. This finding suggests that low SES poses a barrier both to accurate weight perceptions and practices of healthy weight control behavior. Education and income levels may influence perception and health behavior through many potential pathways. Educational attainment directly affects health knowledge [8]. Highly educated people have more of the health and nutrition knowledge and behavioral skills needed for weight control $[5,13]$ and thus are more empowered to incorporate healthy behaviors into their lifestyles [30]. Income primarily determines access to healthy behavior, such as choosing healthful foods and participating in leisure-time physical activities and weight control programs. Conversely, economic constraints restrict individuals' behavioral options and opportunities [8, 30]. In a recent Korean study, low SES was associated with unhealthier dietary patterns [31,32] and limited access to foods of high quality and variety [31]. In addition, low-income people usually experience lack of autonomy in their jobs [30, 33], which might put constraints on the time and efforts required to devote to personal health [13].

Marital status (for women) and alcohol drinking (for men) were also associated with perception and behavior. A woman's marital status may affect her health behavior: traditionally in Korea, married women tend to place more value on family members' wellness than on their own health issues, especially in the realm of preventive activities [28, 34]. In addition, social norms of body size for married women are quite generous unlike those for unmarried women $[35,36]$. Heavy male drinkers were less active in controlling their weight, even though their weight perceptions were not different from those of non- or moderate drinkers. Therefore, heavy drinking can induce obesity by providing high calories from alcohol as well as by hindering healthy weight control behavior. Indeed, clustering of unhealthy behaviors such as heavy drinking, smoking, and physical inactivity have been observed [37]. Given the high prevalence of and rising trends in heavy drinking among Korean men [2], this finding is worrisome.

This study has some limitations. First, our ability to draw causal inference is limited due to the nature of cross-sectional data. Further studies are warranted to prospectively examine whether or not social group inequalities in weight perception and behavior lead to disparities in obesity. Second, the participants' responses might have been influenced by social desirability biases, which more likely affected women [38] and high SES groups [39]. Lastly, we did not have the chance to evaluate specific types of weight perception and behavior (i.e., binge eating, overeating, muscle dysmorphia [40]).

The strengths of this study include use of nationwide data. To our knowledge, this is the largest, nationally representative study in which gender and socioeconomic disparities in weight perception and behavior have been comprehensively described. Our study gave the particular insights in weight perception and weight control behaviors in an Eastern country where evidence is sparse. All data were gathered through structured questionnaires and interviews, and anthropometry was directly measured. We adjusted for many possible confounders.

In conclusion, we found significant gender and SES disparities in weight perception and weight control behavior in Korean adults. These differences may contribute in part to the 
Joh et al.: Gender and Socioeconomic Status in Relation to Weight Perception and Weight Control Behavior in Korean Adults

observed obesity disparities across gender and SES groups. Our findings suggest that, to reverse the obesity epidemic in Korea, raising awareness of obesity in high-risk populations along with structuring physical and socio-cultural environments making healthy behaviors feasible will be needed.

\section{Acknowledgements}

This project was conducted with the support of the Takemi Program in International Health at Harvard School of Public Health. The authors acknowledge the manuscript review of Walter C. Willett, Departments of Nutrition, and Epidemiology, Harvard School of Public Health, and thank Kathy L. Brenner and Sylvia Memolo for the editorial assistance.

\section{Disclosure Statement}

The authors declare that there are no conflicts of interest.

\section{References}

1 World Health Organization. Obesity: Preventing and Managing the Global Epidemic. Report of a World Health Organization Consultation. Geneva, Switzerland: World Health Organization; 2000:256. WHO Obesity Technical Report Series, No. 894.

2 Kim DM, Ahn CW, Nam SY: Prevalence of obesity in Korea. Obes Rev 2005;6:117-121.

3 Ministry for Health, Welfare and Family Affairs: Korea Centers for Disease Control and Prevention. Report on National Health and Nutrition Examination Survey IV (2008). Seoul, Korean Ministry of Health and Welfare, 2009.

4 Yoo S, Cho HJ, Khang YH: General and abdominal obesity in South Korea, 1998-2007: gender and socioeconomic differences. Prev Med 2010;51:460-465.

- 5 Yoon YS, Oh SW, Park HS: Socioeconomic status in relation to obesity and abdominal obesity in Korean adults: a focus on sex differences. Obesity (Silver Spring) 2006;14:909-919.

6 Park HS, Park CY, Oh SW, Yoo HJ: Prevalence of obesity and metabolic syndrome in Korean adults. Obes Rev 2008;9:104-107.

7 Abel T: Cultural capital and social inequality in health. J Epidemiol Community Health 2008;62:e13.

- 8 Sobal J, Stunkard AJ: Socioeconomic status and obesity: a review of the literature. Psychol Bull 1989;105: 260-275.

- 9 Ball K, Mishra GD, Crawford D: Social factors and obesity: an investigation of the role of health behaviours. Int J Obes Relat Metab Disord 2003;27:394-403.

10 Atlantis E, Barnes EH, Ball K: Weight status and perception barriers to healthy physical activity and diet behavior. Int J Obes (Lond) 2008;32:343-352.

11 Timperio A, Cameron-Smith D, Burns C, Crawford D: The public's response to the obesity epidemic in Australia: weight concerns and weight control practices of men and women. Public Health Nutr 2000;3:417-424.

12 Wardle J, Griffith J: Socioeconomic status and weight control practices in British adults. J Epidemiol Community Health 2001;55:185-190.

13 Jeffery RW, French SA: Socioeconomic status and weight control practices among 20- to 45-year-old women. Am J Public Health 1996;86:1005-1010.

14 Burke MA, Heiland FW, Nadler CM: From 'overweight' to 'about right': evidence of a generational shift in body weight norms. Obesity (Silver Spring) 2010;18:1226-1234.

15 Wardle J, Haase AM, Steptoe A: Body image and weight control in young adults: international comparisons in university students from 22 countries. Int J Obes (Lond) 2006;30:644-651.

16 Gregory CO, Blanck HM, Gillespie C, Maynard LM, Serdula MK: Health perceptions and demographic characteristics associated with underassessment of body weight. Obesity (Silver Spring) 2008;16:979-986.

17 Yancey AK, Simon PA, McCarthy WJ, Lightstone AS, Fielding JE: Ethnic and sex variations in overweight selfperception: relationship to sedentariness. Obesity (Silver Spring) 2006;14:980-988.

18 Paeratakul S, White MA, Williamson DA, Ryan DH, Bray GA: Sex, race/ethnicity, socioeconomic status, and BMI in relation to self-perception of overweight. Obesity Res 2002;10:345-350.

19 Chang VW, Christakis NA: Self-perception of weight appropriateness in the United States. Am J Prev Med 2003; 24:332-339. 
Joh et al.: Gender and Socioeconomic Status in Relation to Weight Perception and Weight Control Behavior in Korean Adults

20 World Health Organization Western Pacific Region, International Association for the Study of Obesity, International Obesity Task Force: The Asia-Pacific Perspective: Redefining Obesity and Its Treatment. Sydney, Health Communications Australia Pty, 2000.

21 Gidding SS, Lichtenstein AH, Faith MS, Karpyn A, Mennella JA, Popkin B, Rowe J, Van Horn L, Whitsel L: Implementing American Heart Association pediatric and adult nutrition guidelines: a scientific statement from the American Heart Association Nutrition Committee of the Council on Nutrition, Physical Activity and Metabolism, Council on Cardiovascular Disease in the Young, Council on Arteriosclerosis, Thrombosis and Vascular Biology, Council on Cardiovascular Nursing, Council on Epidemiology and Prevention, and Council for High Blood Pressure Research. Circulation 2009;119:1161-1175.

22 Korean Endocrine Society, Korean Society for the Study of Obesity: Management of Obesity, 2010 Recommendation. Endocrinol Metab 2010;25:301-304.

23 OECD Project on Income Distribution and Poverty, via www.oecd.org/els/social/inequality: What Are Equivalence Scales? www.oecd.org/dataoecd/61/52/35411111.pdf.

24 Petersen MR, Deddens JA: A comparison of two methods for estimating prevalence ratios. BMC Med Res Methodol 2008;8:9.

-25 Fernald LC: Perception of body weight: a critical factor in understanding obesity in middle-income countries. J Womens Health (Larchmt) 2009;18:1121-1122.

26 Holdsworth M, Gartner A, Landais E, Maire B, Delpeuch F: Perceptions of healthy and desirable body size in urban Senegalese women. Int J Obes Relat Metab Disord 2004;28:1561-1568.

27 Jung JH, Forbes BG: Body Dissatisfaction and disordered eating among college women in China, South Korea, and the United States: contrasting predictions from sociocultural and feminist theories. Psychol Women Quart 2007;31:381-393.

28 Jung J, Forbes GB: Multidimensional assessment of body dissatisfaction and disordered eating in Korean and US college women: a comparative study. Sex Roles 2006;55:39-50.

29 Kim OS, Kim KH: Comparisons of body mass index, perception of body weight, body shape satisfaction, and self-esteem among Korean adolescents. Percept Mot Skills 2003;97:1339-1346.

-30 Wardle J, Waller J, Jarvis MJ: Sex differences in the association of socioeconomic status with obesity. Am J Public Health 2002;92:1299-1304.

31 Chul Ahn C Engelhardt K, Joung H: Diet variety is associated with socio-economic factors. Ecol Food Nutr 2006; 45:417-430.

-32 Kim K, Hong SA, Kim MK: Trends in nutritional inequality by educational level: a case of South Korea. Nutrition 2010;26:791-798.

33 Monteiro CA, Moura EC, Conde WL, Popkin BM: Socioeconomic status and obesity in adult populations of developing countries: a review. Bull World Health Organ 2004;82:940-946.

-34 Im E-0, Park YS, Lee EO, Yun SN: Korean women's attitudes toward breast cancer screening tests. Int J Nurs Stud 2004;41:583-589.

35 Jin E: A Comparative study on the self perception of body image in college students. J Korea Acad Publ Health Nurs 2007;21:67-74.

36 Cho G: Cultural influence on the characterizations of health by Korean women living in the United States. Master thesis. Houston, Faculty of the Valenti School of Communication, University of Houston, 2011.

-37 Kang K, Sung J, Kim CY: High risk groups in health behavior defined by clustering of smoking, alcohol, and exercise habits: National Health and Nutrition Examination Survey. J Prev Med Public Health 2010;43:73-83.

38 Hebert JR, Hurley TG, Peterson KE, Resnicow K, Thompson FE, Yaroch AL, Ehlers M, Midthune D, Williams GC, Greene GW, Nebeling L: Social desirability trait influences on self-reported dietary measures among diverse participants in a multicenter multiple risk factor trial. J Nutr 2008;138:226S-234S.

39 Hebert JR, Peterson KE, Hurley TG, Stoddard AM, Cohen N, Field AE, Sorensen G: The effect of social desirability trait on self-reported dietary measures among multi-ethnic female health center employees. Ann Epidemiol 2001;11:417-427.

40 Phillips KA, Wilhelm S, Koran LM, Didie ER, Fallon BA, Feusner J, Stein DJ: Body dysmorphic disorder: some key issues for DSM-V. Depress Anxiety 2010;27:573-591. 